\title{
Reflexões sobre a interpretação marxista da teoria política de Bento Espinosa feita por Ellen Meiksins Wood
}

Juliane Helanski $i^{1}$

\begin{abstract}
Resumo: Bento Espinosa (1632-1677), filósofo que viveu na Holanda do século XVII, não costuma ser estudado nos cursos de Ciências Sociais como um dos precursores da Ciência Política, embora sua teoria política tenha sido retomada por alguns especialistas - tais como Marilena Chauí e Antonio Negri - que mostram que a sua teoria da democracia pode ser profundamente emancipadora. Uma visão diferenciada dessa teoria foi apresentada por outra pesquisadora marxista - Ellen Meiksins Wood - que diverge das demais interpretações, enfatizando aspectos mais conservadores da teoria política do filósofo. Abordamos neste artigo as principais características teórico-metodológicas do contextualismo social por meio de uma reflexão analítica da interpretação marxista da teoria política de Bento Espinosa feita por Ellen Meiksins Wood. Utilizamos o material elaborado por Silva (2016) com base no artigo de Neal Wood (1978) sob a forma de sete tabelas que organizam vários conjuntos de questões, objetivando destacar o que seria relevante no contexto social do autor que está sendo estudado e cuja obra se pretende entender e explicar. Assim, acreditamos exemplificar de forma didática a aplicação do contextualismo social para uma melhor compreensão e explicação do pensamento político de Bento Espinosa.
\end{abstract}

Palavras-chave: Teoria política; Contextualismo Social; Bento Espinosa; Ellen Meiksins Wood.

\section{Reflections on the Marxist interpretation of Bento Espinosa's political theory by Ellen Meiksins Wood}

\begin{abstract}
The dutch philosopher Bento Espinosa (1632-1677) is unusually studied in Social Sciences as one of precursors of Political Science although his political theory has been adopted by some experts such as Marilena Chaui and Antonio Negri - who shows his theory of democracy can be deeply emancipatory. A different view of his theory was presented by another marxist researcher - Ellen Meiksins Wood - who diverges from other interpretations emphasizing more conservative aspects of the philosopher's political theory. In this article, we approach the main theoretical and methodological characteristics of social contextualism through an analytical reflection of the marxist interpretation of Bento Espinosa's political theory by Ellen Meiksins Wood. We used material prepared by Silva (2016) based on article by Neal Wood (1978) in the form of seven spreadsheet that organize several sets of questions, in order to highlight what would be relevant in social context of author under study and whose work if you want to understand and explain. We believe to exemplify in a didactic way application of social contextualism for a better understanding and explanation of Bento Espinosa's political thought.
\end{abstract}

Keywords: Political Theory; Social Contextualism; Benedict Spinoza; Ellen Meiksins Wood.

\footnotetext{
${ }^{1}$ Mestra em Ciências Sociais pela Universidade Estadual do Oeste do Paraná (Unioeste - Toledo) e professora colaboradora de Ciências Sociais na Universidade Estadual do Oeste do Paraná (Unioeste - Foz do Iguaçu). julianhelanski@gmail.com
} 


\section{Introdução}

O interesse no pensamento político de Bento Espinosa (1632-1677) surgiu a partir de algumas reflexões sobre sua teoria da democracia que pode ser considerada profundamente emancipadora - tal como aparece nas interpretações de Marilena Chauí e Antonio Negri. As releituras marxistas da obra espinosana enfatizam aspectos de sua teoria política que fazem parecer lamentável a sua ausência entre os principais clássicos da política - como Maquiavel, Hobbes, Locke e Rousseau - pois retira das reflexões iniciais sobre a formação do Estado moderno elementos que poderiam sugerir desenvolvimentos diferentes dos comuns ao mainstream da Ciência Política. Por isso, com o objetivo de mostrar que Espinosa também mereceria figurar entre os clássicos, explorei algumas reflexões sobre sua teoria política em pesquisas de iniciação científica e depois na pesquisa que gerou a dissertação de mestrado².

Este artigo expõe as principais características teórico-metodológicas do contextualismo social por meio da análise da leitura marxista da teoria política de Bento Espinosa feita por Ellen Meiksins Wood no livro Liberty and Property: a Social History of Western Political Thought from Renaissance to Enlightenment (2012) ${ }^{3}$. Diferente das interpretações de Chaú e Negri, a autora mostra que, quando situado em seu contexto social específico, Espinosa parece menos emancipador e mais integrado ao grupo que pertencia. Realizamos uma análise como o auxílio de um questionário composto por sete tabelas que organizam vários conjuntos de questões sobre os principais aspectos que o leitor deve considerar durante a leitura de uma obra de teoria política. Tais tabelas foram elaboradas por Silva (2016) a partir de Neal Wood (1978) complementado por outras obras do autor $(1974 ; 1978 ; 1984 ; 1991 ; 2002)$ e de sua parceira no empreendimento, Ellen Meiksins Wood (1991; 2002; 2008; 2011a; 2011b), com o objetivo de tornar o contextualismo social mais didático e a obra do teórico político mais compreensível.

Os cientistas políticos marxistas Neal Wood e Ellen Meiksins Wood retomaram o pensamento marxiano para mostrar que, para compreender e explicar o pensamento político "clássico", era essencial realizar a contextualização social dos autores e de suas ideias - método que Neal Wood chamou de "história social da teoria política" [a social history of political thought] e que traduzimos por "contextualismo social". Enfatizam que a teoria política foi escrita por seres humanos envolvidos em condições sociais reais, constituindo uma relação "orgânica" entre as ideias e as práticas políticas, tendo em vista que o contextualismo social parte do princípio de que a história da política consiste em uma atividade prática fundamentada de acordo com interesses objetivos das classes sociais dominantes (humanidade dos teóricos) de uma determinada época e lugar (historicidade dos textos). Assim, o autor que escreve uma obra política está, de alguma forma, engajado nos conflitos sociais do seu tempo.

\footnotetext{
${ }^{2}$ Conferir: HELANSKI, Juliane; SILVA, Vania Sandeleia Vaz. A inclusão dos pobres no sujeito político 'multidão’: a carne monstruosa. In: $6^{\circ}$ Seminário nacional Estado e Políticas Sociais $2^{\circ}$ Seminário de Direitos Humanos. Toledo, 6., 2014. Anais... Toledo: Edunioeste, 2014. SILVA, Vania Sandeleia Vaz; HELANSKI, Juliane; Bento Espinosa (1632-1677) e a teoria das formas de governo. Revista Tempo da Ciência, v. 21, n. 42, 2014. SILVA, Vania Sandeleia Vaz. Duas perspectivas pós marxistas do poder do Estado sobre o Império: Ellen Meiksins Wood versus a parceria Michael Hardt e Antonio Negri. In: XI Semana Acadêmica de Ciências Sociais, 10., Toledo. Anais... Toledo: Edunioeste, 2014. SILVA, Vania Sandeleia Vaz. O poder constituinte da multidão em Espinosa. In: XIX Simpósio de Filosofia Moderna e Contemporânea da Unioeste, Toledo, 19., Toledo. Anais... Toledo: Edunioeste, 2014.

${ }^{3}$ A exposição desse artigo tem como base o capítulo três da minha dissertação de mestrado em Ciências Sociais intitulada "Contextualismo social na prática: a interpretação da teoria política de Bento Espinosa feita por Ellen Meiksins Wood" (HELANSKI, 2017). Os outros dois capítulos iniciais fazem uma análise da interpretação do pensamento político espinosano feita por Antonio Negri e Marilena Chauí, ambos marxistas, e por Leo Strauss que, apesar de partir de uma posição política conservadora, chegou a uma conclusão muito semelhante à dos marxistas.

${ }^{4}$ Durantes as reflexões realizados nos encontros do Grupo de Pesquisa Democracia e Desenvolvimento, composto por professores e estudantes do curso de Ciências Sociais da Unioeste, campus de Toledo, o professor Geraldo Magella Neres sugeriu que contextualismo social parecia a expressão mais adequada para nos referirmos à metodologia desenvolvida por Neal Wood e Ellen Meiksins Wood, conforme explicamos no artigo "Como estudar teoria política: textualismo, contextualismo linguístico e contextualismo social” (HELANSKI; NERES; SILVA, 2016).
} 


\section{Como Ellen Meiksins Wood interpreta a teoria política de Bento Espinosa?}

Para compreender melhor como realizar uma contextualização social de um autor clássico da política, a proposta foi analisar em que medida uma das elaboradoras do método - Ellen Meiksins Wood - respondeu as questões que são apresentadas por Neal Wood (1978). A seguir, apresento cada tabela (tal como aparece em Silva, 2016) seguida das respostas encontradas na análise realizada por Ellen Wood, destacando em que medida ela "respondeu" as questões que o contextualismo social considera relevante para o estudo de uma obra de teoria política. As sete tabelas citadas neste artigo servem para facilitar o entendimento do contextualismo social e orientar o leitor, por isso, não devem ser tomadas à risca, ou seja, não é obrigatório que todas as questões tenham respostas. Inclusive, verificamos que nem mesmo Ellen Wood respondeu todas as questões propostas. O primeiro conjunto de questões relaciona as ideias do teórico com a estrutura de classes e os conflitos sociais:

Tabela 1. Aspectos relacionados ao contexto social em que o autor escreveu a obra em análise, que permitem compreender como suas ideias se relacionam com a estrutura de classe e o conflito social

\begin{tabular}{|l|l|}
\hline $\mathbf{1}$ & Quais classes estão ascendendo e quais estão declinando? \\
\hline $\mathbf{2}$ & Qual o grau de consciência de classe [class consciousness]? \\
\hline $\mathbf{3}$ & A estrutura de classes está refletida nos arranjos governamentais? \\
\hline $\mathbf{4}$ & A estrutura de classes está refletida no sistema de dominação e subordinação? \\
\hline $\mathbf{5}$ & Como as divisões religiosas na sociedade estão relacionadas com a vida econômica e política? \\
\hline $\mathbf{6}$ & Como as divisões étnicas na sociedade estão relacionadas com a vida econômica e política? \\
\hline $\mathbf{7}$ & Quais os modelos aceitáveis de conduta social? \\
\hline $\mathbf{8}$ & Quais as várias tendências intelectuais ou escolas de pensamento? \\
\hline $\mathbf{9}$ & Quais são seus temas centrais? \\
\hline $\mathbf{1 0}$ & De que modo estes temas estão relacionados com as lutas sociopolíticas do período? \\
\hline $\mathbf{1 1}$ & Podemos nos referir às raízes sociais do conflito intelectual? \\
\hline $\mathbf{1 2}$ & As linhagens intelectuais refletem as divisões de classe ou outras clivagens sociais? \\
\hline
\end{tabular}

Fonte: Silva (2016, p. 90).

Ellen Meiksins Wood (2012) analisou minuciosamente os conflitos sociais do contexto de Espinosa para mostrar como a sua teoria política condizia com os interesses das classes dominantes e cumpria uma função "ideológica" importante: a condição de um ser humano histórico que escrevia engajado e comprometido com problemas sociais e políticos de sua época. A autora explica que Espinosa (1632-1677) viveu durante um intenso ciclo de conflitos marcados pelo declínio da nobreza orangista e a ascensão de diversos grupos comerciais urbanos (e, depois, a derrota das elites comerciais pelos monarquistas). Essas disputas (pequenas guerras civis) pelo controle do poder econômico e político das cidades-Estado também ocorriam entre as próprias elites cuja consequência era um entrave ao desenvolvimento econômico pré-capitalista. Por isso, as elites almejavam um governo republicano que respeitasse as liberdades individuais e preservasse a autonomia das cidades-Estado para que pudessem prosperar com relativa independência umas das outras. Outros tipos de conflitos acabaram surgindo, envolvendo controvérsias religiosas e étnicas entre vários segmentos protestantes (republicanos) e católicos (monarquistas). Espinosa viveu na cidade-Estado da Holanda, que, no seu tempo, era a economia mais desenvolvida e o centro urbano mais propício e tolerante ao desenvolvimento intelectual do período no contexto europeu (HELANSKI, 2017). 
Segundo Ellen Meiksins Wood (2012), as elites conciliaram as ideias republicanas de Espinosa com as ideias monarquistas de Thomas Hobbes, em voga na vizinha Inglaterra, aos seus preceitos políticos e econômicos. Assim, as elites passaram a operar politicamente, partindo do princípio de estabilidade e equilíbrio das paixões individuais da avidez e da ganância consideradas naturais aos seres humanos. Tudo isso assimilado sob a forma de um governo que não fosse questionado, ou seja, absoluto, mas que respeitasse as liberdades republicanas. A liberdade individual de busca pelo lucro e acúmulo de riquezas deveria servir aos interesses comuns das elites, sustentando o seu domínio sem gerar grandes instabilidades entre si. Essa visão sobre a natureza humana e a prática política pode ser lida como prescrição de uma determinada conduta social: pequenas repúblicas governadas por um conjunto de oligarquias comerciais ricas que justificariam seu poder econômico e político como algo natural e zeloso ao bem-estar de todos (HELANSKI, 2017).

Assim, as elites comerciais holandesas prosperaram e construíram um grande mercado de arte e comércio internacional impulsionado pelas suas descobertas em navegação. O crescimento da densidade populacional urbana dos Países Baixos propiciou e produziu o desenvolvimento e a circulação de ideias artísticas e científicas incomum para a época. A Holanda de Espinosa se tornou o lugar mais tolerante e o maior centro de inovação intelectual europeu, e, dentro de certos limites, um destino seguro para intelectuais e religiosos perseguidos. Essas ideias republicanas causaram efeitos ambíguos e contraditórios na vida política e social holandesa, pois as elites comerciais conquistaram suas liberdades e o autogoverno às expensas de argumentos em defesa das classes mais populares. Embora argumentassem a favor do papel político ativo das pessoas, em geral, faziam de tudo para limitar o acesso universal aos direitos políticos. Ellen Wood (2012) chama as elites comerciais de "oligarquias" porque visavam perpetuar suas bases políticas estreitas com o apoio, mas sem a participação popular (HELANSKI, 2017).

Outros grupos sociais importantes da sociedade holandesa, as corporações de ofícios, não participavam das disputas pelo poder político que ficavam restritas às oligarquias comerciais. Além do mais, quando a população trabalhadora das guildas e das milícias tiveram algum espaço na disputa política - o que resultou, em 1628, na expulsão do regente republicano Oldenbarnevelt e na prisão de Hugo Grotius - foi usada como fonte de agitação pelos monarquistas que tornou o poder político popular ainda mais restrito. Os monarquistas fizeram uma reviravolta e conseguiram conquistar o apoio das forças populares para derrotar de vez a oposição oligárquica das elites comerciais (HELANSKI, 2017).

Os amigos pessoais de Espinosa (figuras políticas como Veltuysen, os irmãos de La Court e Johan de Witt) apoiavam uma república "mais aberta" e eleita pelos cidadãos "de posses". Por isso, não era viável que houvesse o governo de uma única elite comercial, pois a abertura aos diferentes grupos facilitaria a consolidação dos interesses econômicos e políticos das elites em geral. Como não havia consenso sobre um governo misto entre as próprias elites comerciais, elas tiveram que pensar em como atrair as forças populares para longe dos interesses dos monarquistas. Segundo Wood (2012), a saída foi introduzir elementos democráticos em uma república oligárquica ${ }^{5}$. Mas as elites não conseguiram superar suas próprias divisões internas, o que facilitou a vitória do poder monárquico orangista com o final da Guerra dos Oitenta Anos (1648) e a independência dos Países Baixos da Espanha. Esse foi o contexto que fomentou a teoria política de Espinosa (HELANSKI, 2017).

A tese de Ellen Wood no artigo "The Question of Market Dependence" (2002, p. 52-61), é que a República holandesa dependia de um mercado externo altamencompetitivo, não capitalista, porque não havia uma competição de preços entre produtores de mercadorias particulares, mas um concurso entre comerciantes ou entre cidades comerciais pelo controle das redes de mercado. O instrumento para conseguir tal harmonia não era a chamada "mão invisível" do mercado, nem a "economia política", mas um "governo republicano", em que a riqueza era critério de ingresso no escritório público. Ou seja, os benefícios públicos derivavam dos interesses privados e as competições dos interesses econômicos

\footnotetext{
${ }^{5}$ Ellen Meiksins Wood chamou essa configuração de poder social de "sociedade comercial constituída politicamente", onde os interesses econômicos eram inseparáveis do status e do privilégio cívico e político. Ver: Wood, Ellen Meiksins. The Question of Market Dependence. Journal of Agrarian Change, v. 2, n. 1, p. 50-87, jan. 2002.
}

85 
harmonizavam-se e configuravam-se de acordo com o que consideravam o "bem comum". O que distinguia a república holandesa do capitalismo de mercado da Inglaterra, por exemplo, era a concepção de que a harmonia do comércio poderia ser cuidadosamente balanceada com as instituiç,óes politicas (HELANSKI, 2017, p. 123).

O segundo conjunto de questões orienta a busca pelos aspectos biográficos de Espinosa a fim de situá-lo na estrutura de classes e conflito social para identificar a natureza do seu comprometimento político, analisando detidamente suas conexões com pessoas que foram relevantes na sua formação e sobrevivência, e, possibilitando saber o quanto podem ter influenciado suas opções teóricas.

Tabela 2. Aspectos relacionados à biografia que permitem situar o autor na sociedade

\begin{tabular}{|l|l|}
\hline $\mathbf{1}$ & Quem era a família do teórico e quais suas conexões familiares? \\
\hline $\mathbf{2}$ & Como foi sua educação e também sua formação intelectual? \\
\hline $\mathbf{3}$ & Quem eram seus amigos e associados? Sua educação? Sua religião? Sua situação econômica? \\
\hline $\mathbf{4}$ & Qual a sua profissão, ofício ou ocupação? \\
\hline $\mathbf{5}$ & Quem era seu empregador ou patrão? \\
\hline $\mathbf{6}$ & Qual era seu estatuto legal? \\
\hline $\mathbf{7}$ & Quais suas funções econômicas reais? \\
\hline $\mathbf{8}$ & Quais as fontes e a extensão de sua renda? \\
\hline $\mathbf{9}$ & Como era seu modo de vida? \\
\hline $\mathbf{1 0}$ & Quais suas atividades políticas? \\
\hline $\mathbf{1 1}$ & Quais suas afiliações políticas? \\
\hline $\mathbf{1 2}$ & Quais seus laços religiosos? \\
\hline $\mathbf{1 3}$ & Qual o gênero/identidade/orientação sexual (heteronormatividade)? \\
\hline $\mathbf{1 4}$ & Qual sua "etnia" e qual a situação dessa na sociedade em questão? \\
\hline
\end{tabular}

Fonte: Silva (2016, p. 92).

Espinosa nasceu em Amsterdã em 1632, foi filho de família judia portuguesa comerciante que encontrou refúgio na Holanda por causa da intolerância e perseguição religiosa de Portugal. Durante a sua juventude, Espinosa se dedicou ao estudo do judaísmo, no entanto, devido a sua obra máxima Ética foi excomungado da comunidade judaica, deserdado de sua família e denunciado pela Igreja Católica ${ }^{6}$. Foi assim que Espinosa estabeleceu conexões com os pensadores protestantes calvinistas cartesianos. Johan de Witt, um famoso membro das elites comerciais, foi amigo e protetor de Espinosa. Inclusive, as ideias políticas e filosóficas mais influentes da época circulavam entre as elites comerciais. Em 1672, a França e a Alemanha tomaram os Países Baixos, assassinaram Johan de Witt e restauraram o regime monarquista contando com o apoio popular - governo que Espinosa temeu até a sua morte em 1677. Ellen Wood (2012) destaca que Espinosa foi um filósofo inovador e suas ideias filosóficas certamente foram radicais e além do debate do seu tempo, mas, são as suas ideias políticas que exercem uma força determinante incontestável no seu pensamento como um todo (HELANSKI, 2017).

\footnotetext{
${ }^{6}$ Marilena Chauí é uma grande representante do "marxismo espinosano brasileiro" e fez um estudo detalhado sobre a vida de Espinosa, apesar de não ter explicado a exclusão das mulheres da teoria sobre a democracia de Espinosa. Ver: CHAUÍ, Marilena. A Nervura do Real: imanência e liberdade em Espinosa. São Paulo: Companhia das Letras, 1999; 
Ellen Wood não especifica qual era o status econômico ou quais eram os meios específicos de sobrevivência de Espinosa, mas diz que ele recebia proteção econômica de Johan de Witt, o que sugere algum tipo de apoio financeiro. Sobre suas atividades políticas, Ellen Wood diz (2012) que Espinosa foi, acima de tudo, um filósofo, porém, um filósofo politicamente engajado e partidário dos interesses das elites republicanas. Silva (2016) chama a atenção para a importância das questões sobre a etnia, o gênero, a identidade e a orientação sexual, atualmente imprescindíveis para compreender a situação política do autor (essas informações não foram verificadas por Ellen Wood, talvez não fosse uma questão importante no tempo de Espinosa, mas não quer dizer que não estava presente). Ellen Wood (2012) finaliza o segundo conjunto de questões salientando que, apesar de Espinosa ter vivido modestamente, suas ideias políticas ajudaram a legitimar o modo de vida burguês de seus amigos (HELANSKI, 2017).

O terceiro conjunto de questões (pode ser analisado juntamente com o quarto conjunto, que trata das prescrições para a realização do ideal humano) investiga o "ideal humano" para obter mais informações sobre a classe social com a qual o teórico estava comprometido. Conforme Neal Wood (1978), o "ideal humano" possui uma influência prática que pode decidir a aceitação ou a rejeição de certos objetivos ou fins e a escolha ou elaboração de certos meios - tais como os tipos de instituições políticas e arranjos sociais vislumbrados em uma determinada época - configurando as parcerias partidárias e posicionamentos diante dos conflitos sociais.

Tabela 3. Aspectos relacionados ao ideal humano - herói e anti-herói do teórico clássico

\begin{tabular}{|l|l|}
\hline $\mathbf{1}$ & Como o teórico pensa que os seres humanos devem ser e agir? \\
\hline $\mathbf{2}$ & Que tipo de ser humano deve dominar a sociedade? \\
\hline $\mathbf{3}$ & Que tipo humano - real ou imaginado - carrega a melhor promessa para o futuro? \\
\hline $\mathbf{4}$ & Como o teórico visualiza o indivíduo que mais plenamente realiza esse potencial humano? \\
\hline $\mathbf{5}$ & Quem na sociedade como está atualmente constituída é mais capaz de atingir esse ideal? \\
\hline $\mathbf{6}$ & Esse ideal é atingível por qualquer um ou apenas por poucos? \\
\hline $\mathbf{7}$ & O abismo entre os homens que existem e o ideal humano é grande ou pequeno? \\
\hline $\mathbf{8}$ & Sob quais condições pode o ideal humano ser mais rapidamente realizado? \\
\hline
\end{tabular}

Fonte: Silva (2016, p. 93).

Ellen Wood (2012) afirma que Espinosa escreveu que os seres humanos são ávidos e gananciosos por natureza, diante disso, não seria possível alterar quem eles são, porém, ele acreditava que seria possível encontrar maneiras por meio de um governo que direcionasse a avidez e a ganância para o proveito do Estado e da sociedade em geral (HELANSKI, 2017).

Concluo, portanto, que aqueles vícios que são comuns em tempo de paz, dos quais estamos aqui a falar, nunca devem ser proibidos direta, mas indiretamente, quer dizer, lançando fundamentos do estado que façam, não que a maioria procure viver sabiamente, porque isso e impossível, mas que se conduza pelos afetos que mais uteis sejam para a república. Assim, deve mormente procurar-se que os ricos sejam, se não parcos, pelo menos avaros. Com efeito, não há dúvida de que, se este afeto da avareza, que é universal e constante, for alimentado pelo desejo de glória, a maioria dos homens colocara sem peso o maior empenho em aumentar o que é seu, por forma a ter acesso as honras e a evitar a suprema vergonha (ESPINOSA, 2009, p. 133, grifos do autor).

Para Ellen Wood (2012), esse trecho do Tratado Politico pode ser esclarecedor para a interpretação da teoria política de Espinosa. Alguns marxistas contemporâneos têm visto um potencial revolucionário na teoria sobre a democracia de Espinosa. Entre eles, destaca-se o projeto político-filosófico de Antonio 
Negri (1981; 2000), primeiro, sozinho, e, depois, em parceria com Michael Hardt (2005) ${ }^{7}$, que, segundo Ellen Wood, é incompatível e contraditória, teoricamente e com a visão prática que Espinosa tinha da política, mas que era totalmente consistente e correspondente com os interesses políticos e econômicos das "oligarquias comerciais holandesas". O texto específico que Espinosa deixou sobre a democracia têm apenas quatro parágrafos, porque ele morreu antes que pudesse terminar; os quatro parágrafos são literalmente antidemocráticos porque começa tratando das regras de exclusão das mulheres, dos "servos" e dos estrangeiros da política. A partir disso, Ellen Wood (2012) busca evidências histórias e nas próprias obras de Espinosa de que a sua teoria política "refletia" as práticas políticas das elites comerciais - ela complementa que o mais próximo que essas elites chegaram da democracia foi quando reivindicaram as liberdades republicanas com o intuito de extinguir a monarquia e estabelecer um regime político aberto e tolerante para elas próprias (HELANSKI, 2017).

O quinto conjunto de questões faz a relação entre a teoria política e o contexto social mais amplo (SILVA, 2016). Neal Wood (1978) explica que o contexto social do autor faz parte de um processo histórico feito de continuidades e descontinuidades, permanência e fluxo entre o passado, o presente e o futuro. O teórico pode transcender a sua realidade e criar um sistema de ideias válido para outros tempos e lugares (nesse sentido é universal, mas não absoluto), bem como pode ser uma resposta criativa, crítica e reflexiva sobre determinada força social que se pretende apoiar ou contrariar. Mesmo as ideias transhistóricas, para serem compreendidas, exigem que se realize um estudo da relação entre a teoria e a prática contexto social do autor. Por isso, o objetivo desse conjunto de questões é delimitar a especificidade histórica das ideias do teórico (HELANSKI, 2017).

Tabela 4. Prescrições para realização do ideal humano

\begin{tabular}{|l|l|}
\hline $\mathbf{1}$ & Quem deve governar? \\
\hline $\mathbf{2}$ & Quem deve ser governado? \\
\hline $\mathbf{3}$ & Como os governantes devem governar? \\
\hline $\mathbf{4}$ & Como os governados devem obedecer? \\
\hline $\mathbf{5}$ & $\begin{array}{l}\text { Quão grande é a distância que existe entre a situação sociopolítica real na qual o teórico está } \\
\text { escrevendo e sua visão de uma ordem cívica reconstituída na qual seu ideal humano típico } \\
\text { pode florescer? }\end{array}$ \\
\hline $\mathbf{6}$ & Como essa lacuna pode ser preenchida? \\
\hline
\end{tabular}

Fonte: Silva (2016, p. 94).

A partir da interpretação de Ellen Wood (2012) explanada nas tabelas anteriores, podemos concluir que quem deveria governar seriam as elites comerciais urbanas, que, de fato, governaram durante quase toda a vida de Espinosa. Dessa maneira, a conduta social e o ideal humano se realizariam pelo governo das elites, assim, todos os demais deveriam ser governados. Os governantes deveriam governar controlando a avidez e a ganância humana, guiando os governados para que se tirasse maior proveito para o desenvolvimento econômico e político das elites e da sociedade em geral. Como as elites governaram por um período, podemos dizer que não havia um distanciamento problemático entre a situação sociopolítica real e a visão política de Espinosa. Apesar do ideal político espinosano ter se realizado parcialmente no seu respectivo contexto social, temos que considerar as dificuldades implicadas pelos intensos conflitos políticos, religiosos e culturais que dificultavam sua realização efetiva e que acabou derrotada pelos monarquistas (HELANSKI, 2017).

\footnotetext{
7 Podemos notar o "encantamento" da interpretação de Antonio Negri pelos títulos de suas obras. Ver: NEGRI, Antonio. A Anomalia selvagem: poder e potência em Spinoza. Rio de Janeiro: Editora 34, 1981; Spinoza subversivo. Madri: Akal, 2000. E, depois em parceria com Michael Hardt: HARDT, Michael; NEGRI, Antonio. Império. Rio de Janeiro: Record, 2012; . Multidão: guerra e democracia na era do Império. Rio de Janeiro: Record, 2005.
} 
Tabela 5. Delimitar a especificidade histórica das ideias do teórico

\begin{tabular}{|l|l|}
\hline $\mathbf{1}$ & O que os autores clássicos estavam tentando dizer aos seus contemporâneos? \\
\hline $\mathbf{2}$ & Sob quais condições estavam dizendo isso? \\
\hline $\mathbf{3}$ & Por que e com quais interesses estavam dizendo isso? \\
\hline
\end{tabular}

Fonte: Silva (2016, p. 97).

A especificidade histórica das ideias do teórico nos permite delimitar o que era próprio e tinha valor somente para o contexto de Espinosa e o que poderia ter validade trans-histórica em relação a outros tempos e contextos sociais. Como, por exemplo, o período anterior ao nascimento e após a morte de Espinosa, que podem ser relevantes para compreender as origens e os possíveis efeitos posteriores de suas ideias, embora algumas ideias tenham validade somente para o período em que o autor viveu (SILVA, 2016).

De acordo com Neal Wood (1978), não podemos isolar o contexto social a ponto de isolá-lo do processo histórico, tornando-o a-histórico, apesar das especificidades de cada época, há continuidades entre o passado e o presente que são esclarecedores para uma determinada atualidade: como a existência de organizações e instituições sociais e políticas; padrões, regras e valores sociais. A posição de Neal Wood adquire um caráter mais brando sobre a utilização das ideias de um autor fora de seu contexto sem configurar anacronismos, porque a complexidade das ideias pode transcender e desafiar os limites do seu próprio tempo histórico e acabar servindo para orientar as condutas políticas em outros tempos e lugares (HELANSKI, 2017).

Desse modo, poderíamos dizer que as leituras marxistas espinosanas, como a de Antonio Negri e Michael Hardt, podem fazer sentido? O que podemos retomar do pensamento político de Espinosa que pode ser usado para interpretar nossa realidade política hoje? Será que a exclusão deliberada das mulheres e dos indivíduos "dependentes economicamente" podem ser irrelevantes a ponto de fundamentar uma teoria liberatória e revolucionária sobre a democracia na contemporaneidade?

O sexto conjunto de questões analisa os elementos "ideológicos" da teoria política. De acordo com Silva (2016), a construção das ideias do teórico é feita a partir de uma estrutura sistemática de pensamento. Neal Wood (1978) enfatiza que o exercício de teorização exige o uso e o aperfeiçoamento das ideias de acordo com conhecimentos científicos, históricos, teológicos, psicológicos, éticos, metafísicos, epistemológicos, entre outros. Porém, o uso de determinadas técnicas e análises filosóficas, a omissão consciente ou deliberada de certos fatos, a contraposição de argumentos, a ênfase em determinados assuntos etc. formam uma "ideologia". As ideologias podem servir como ferramentas para convencer um público, para revelar os interesses partidários do teórico ou podem ocultar aspectos da realidade social - diferente da apelação emocional ou da distorção deliberada dos fatos, frequentemente utilizada pelos "propagandistas" da política (HELANSKI, 2019).

Tabela 6. O Teórico da Política (diferente dos ideólogos):

\begin{tabular}{|l|l|}
\hline $\mathbf{1}$ & Está escrevendo para uma audiência selecionada com muito conhecimento intelectual; \\
\hline $\mathbf{2}$ & Tenta convencer seus leitores por meio de uma complexa argumentação racional; \\
\hline $\mathbf{3}$ & Está menos interessado em apelos puramente emocionais e instintivos; \\
\hline $\mathbf{4}$ & Não pretende "mover" a audiência para a ação imediata ou extrema \\
\hline
\end{tabular}

Fonte: Silva (2016, p. 99). 
Segundo Ellen Wood (2012), Espinosa escrevia para um grupo de intelectuais que ficou conhecido como os "livres pensadores protestantes", filósofos renomados e frequentadores do chamado "Círculo Cartesiano", que, sob a influência de Descartes, constituíram um tipo de "republicanismo cartesiano". Espinosa também deixou evidente as influências de Descartes, Hobbes e Maquiavel em seu pensamento político por meio de referências diretas a esses autores. Se o pensamento político de Espinosa "refletia" ou "representava" os interesses das elites comerciais, quer dizer que também estava orientando as suas ações (HELANSKI, 2019).

O sétimo e último conjunto de questões visa identificar a estrutura básica da teoria política demonstrando as suas implicações em relação às circunstâncias sociais concretas. Por exemplo, o "direito natural" pressupõe a existência da noção de "indivíduo" e de "coletividade" moderna, o que implica determinado grau de desenvolvimento econômico, científico e religioso. Por isso, a compreensão dos princípios básicos estruturais depende das condições históricas específicas de sua emergência.

Tabela 7. Quais os destinatários das ideias do autor?

\begin{tabular}{|l|l|}
\hline $\mathbf{1}$ & Para quais grupos específicos e indivíduos na sociedade os princípios se aplicam? \\
\hline $\mathbf{2}$ & Por que para estes grupos e indivíduos e não para outros? \\
\hline $\mathbf{3}$ & Para quais direitos ou desejos em questão - em caso de conflito - será dada prioridade e por quê?? \\
\hline $\mathbf{4}$ & Para quais vantagens ou interesses está a particular hierarquia de desejos ou direitos? \\
\hline
\end{tabular}

Fonte: Silva (2016, p. 100).

Ellen Wood (2012) concluiu que os princípios fundamentais da teoria política de Espinosa estavam diretamente relacionados e "refletindo" os interesses econômicos e políticos, e as ideias republicanas das elites comerciais holandesas - que desempenharam um papel político importante na luta pelas liberdades republicanas, mas que também personificavam naquele momento a classe mais apta para governar. Em meio aos conflitos, a prioridade às elites comerciais na teoria política de Espinosa ficou evidente pela sua defesa de um governo das "oligarquias comerciais" contra os monarquistas orangistas. Diante disso, as vantagens serviam aos interesses das elites comerciais, que visavam manter seu poder político para que pudessem perpetuar sua dominância econômica (HELANSKI, 2017).

\section{Uma democracia “oligárquica"?}

Ellen Wood (2012) concluiu que a teoria sobre a democracia de Bento Espinosa não pode ser pensada e utilizada em termos democráticos como entendemos uma democracia na atualidade. As evidências históricas delimitadas com o auxílio do contextualismo social sugerem que o pensamento político de Espinosa servia aos interesses econômicos e políticos das elites comerciais holandesas, que não tinham interesses democráticos. Ellen Wood reconhece que Espinosa rompeu com paradigmas filosóficos importantes no seu tempo, no entanto, suas ideias propriamente políticas parecem não ter sido revolucionárias e liberatórias, como a leitura marxista de Antonio Negri e Michael Hardt acreditam a ponto de fundamentar um projeto político emancipatório. A defesa de Espinosa a um governo de caráter aristocrático e oligárquico é evidente - como podemos observar a partir de suas advertências à inclusão política das classes mais populares e à exclusão deliberada das mulheres, dos estrangeiros, dos criminosos e dos indivíduos que precisam trabalhar para sobreviver.

Entretanto, Espinosa escreveu no Tratado Teológico-político que a democracia é o mais natural dos regimes políticos porque melhor coincide com a liberdade natural e à autopreservação individual. Porém, ao distinguir a aristocracia da democracia no Tratado Político, Espinosa afirma que uma aristocracia bemsucedida deve contar com grande número de patrícios, e mesmo que toda uma população fosse admitida no patriciado, ainda assim seria uma aristocracia porque o direito à entrada depende da escolha expressa. Do mesmo modo, um Estado continuaria sendo democrático mesmo que o direito de governar pertencesse a uma minoria, pois as regras de participação não dependem da escolha. 
Penso, com sito ter mostrado com clareza bastante os fundamentos do Estado democrático, do qual eu preferi tratar antes de todos os outros, porque me parecia o mais natural e o que mais se aproxima da liberdade que a natureza concede a cada um. Em democracia, com efeito, ninguém transfere o seu direito natural para outrem ao ponto de este nunca mais ter de o consultar daí em diante: transfere-o, sim, para a maioria do todo social, de que ele própria faz parte, e, nessa medida, todos continuam iguais, tal como acontecia anteriormente no estado de natureza. Em segundo lugar, quis tratar expressamente só deste Estado, porque é o que melhor convém ao objetivo que eu me propus, a saber, tratar da utilidade da liberdade na república (ESPINOSA, 2004, p. 332, grifos do autor).

[...] A principal diferença entre o estado aristocrático e o democrático é, com efeito, esta: no aristocrático o direito de governar depende unicamente da escolha, ao passo que no democrático ele depende acima de tudo de um certo direito inato ou adquirido por fortuna, como a seu tempo diremos. Assim, mesmo que a multidão de um estado estej a toda incluida no número dos patrícios, desde que esse direito não seja hereditário nem transmissivel a outros por una lei comum, o estado será totalmente aristocrático, na medida em que ninguém, a não ser os expressamente escolbidos, está incluído no número dos patrícios (ESPINOSA, 2009, p. 87-88, grifos do autor).

Inicialmente, a interpretação de Ellen Wood pode parecer determinista, uma vez que ela é enfática em dizer que a teoria política de Espinosa não teria nada de democrática e correspondia aos interesses das "oligarquias comerciais" holandesas. Primeiro, ela diz que se olharmos para o seu contexto veremos que as suas ideias estavam "refletindo" os interesses das elites comerciais holandesas em justificar e manter seu poder e domínio econômico e político. Segundo, os últimos parágrafos do Tratado Político sobre a exclusão e a inferioridade "natural" e "social" das mulheres invalidam quaisquer interpretações e usos emancipatórios ou revolucionários da teoria sobre a democracia de Espinosa na atualidade - mesmo que se diga e se reconheça que Espinosa estava limitado pelo seu próprio tempo ou que ele tenha cometido incongruências filosóficas sérias no seu pensamento.

Ellen Wood diz que, por mais que as ideias monistas e materialistas sobre a democracia de Espinosa fossem singulares em relação aos demais pensadores políticos do início da modernidade, não quer dizer que Espinosa possa fundamentar um projeto político radicalmente democrático hoje (o que também não quer que Espinosa não tenha seus méritos e não mereça ser lido). ${ }^{8}$ Como, por exemplo, Jonathan Israel, lembra Ellen Wood, que visualizou em Espinosa o fundador do liberalismo devido às suas ideias sobre as liberdades individuais; que podem, inclusive, ter influenciado uma corrente iluminista mais radical, fornecendo base para as modernas democracias liberais em relação às liberdades individuais de pensamento, expressão, imprensa, erradicação da autoridade religiosa na educação e na legislação, na separação entre Igreja e Estado etc. (HELANSKI, 2017).

A leitura "textualista" e filosófica de Leo Strauss (1959; 2015) também chegou a conclusões semelhantes ao dizer que seria possível associar a teoria política de Espinosa aos fundamentos do liberalismo, e que provavelmente Espinosa colaborou intelectualmente com o governo das elites comerciais. Apesar de Ellen Wood ter partido de uma orientação marxista, ela parece estar mais de acordo com Jonathan Israel e Leo Strauss do que com Antonio Negri e Michael Hardt (e com Marilena Chauí, que ela não cita e provavelmente tenha desconhecido sua existência). Segundo Ellen Wood, as leituras de Espinosa não teriam sido tão radicais se tivessem realizado uma análise do contexto social em que ele

\footnotetext{
${ }^{8}$ Ellen Wood diz que se quisermos buscar no passado uma fundamentação para se pensar uma democracia realmente racial e emancipatória, poderíamos analisar o contexto da Guerra Civil Inglesa e o exército de Cromwell, os Levellers e os Diggers; movimento que formou uma multidão de pequenos proprietários rurais, artesãos, soldados de baixo escalão etc.; que foram pouco lembrados pela história do pensamento político, mas que se apresentam de forma muito mais democrática do que as interpretações "marxistas espinosana” sugerem (HELANSKI, 2017).

${ }^{9}$ Leo Strauss $(1959 ; 2015)$ concluiu que a democracia em Espinosa é "a forma de governo mais racional porque objetiva garantir o conforto e a segurança para todos e, é a forma mais natural porque cumpre o desejo dos homens de governarem e não serem governados; todavia, a multidão não pode governar porque é sub racional e a democracia é um governo racional; por isso, quem governa são os ricos e esclarecidos porque são racionais; e é a forma que melhor concretiza as liberdades individuais, portanto, a religião civil não deve ser ortodoxa", a partir disso, argumentou que a teoria da democracia em Espinosa é liberal e de origem religiosa (HELANKSI, 2017, p. 83).
}

91 
viveu, em que a prática política da república holandesa, governada pelas elites comerciais, condizia diretamente com o seu pensamento político (HELANSKI, 2017).

A definição de democracia de Espinosa no Tratado Político mais parece uma aristocracia ou uma oligarquia do que com uma democracia emancipatória como acreditam os "marxistas espinosanos". Mesmo na época de Espinosa, a palavra democracia significava um "governo pelo povo", portanto, é crível que fosse recusada porque significaria um governo da "plebe", o que ameaçaria o domínio econômico e político das classes proprietárias. Os argumentos de Espinosa mais favoráveis à constituição política mista também favoreciam ao governo do tipo oligárquico (se não monárquico, pois, na sua concepção, qualquer forma de governo é originariamente democrática porque teria como base o poder do povo). Enfim, não é porque Espinosa usou muito a palavra democracia que sua teoria é democrática. Sua ênfase na democracia no Tratado Teológico-politico pode significar que ele talvez tenha sido mais ou menos democrata no início de sua produção intelectual, mas que depois pode ter se exaurido pelas derrotas do seu contexto histórico - vitória sangrenta dos orangistas e a restauração de um governo monárquico apoiado pelo povo - e tenha redefinido o sentido da democracia (HELANSKI, 2017).

Quando Espinosa afirma que a democracia é uma forma de governo em que a soberania seria mais absoluta, ele está tentando provar que uma aristocracia suficiente numerosa é mais benéfica do que o governo de um único homem.

Para Espinosa, o Estado aristocrático em que um número "adequado" de pessoas "participa" do poder ou do governo é superior à monarquia - em que "um" está em "confronto" com "muitos" - de acordo com sua regra da proporcionalidade -, sobretudo porque o regime aristocrático é mais próximo do Estado absoluto - democrático, no qual "todos os cidadãos" participam do governo. Para ele, um Estado é aristocrático "porque o poder pertence não a um só, mas a alguns, escolhidos na massa da população" sendo que denomina os "escolhidos" como "patrícios" (HELANSKI; SILVA, 2014, p. 102).

Ellen Wood (2012) acredita ter trazido evidências históricas o suficiente para mostrar que a definição de democracia de Espinosa foi cuidadosamente planejada para incluir um tipo de república oligárquica - o que nos leva a acreditar que Espinosa tratava a democracia e a república como sinônimos.

A preferência de Espinosa pela "república livre" como sinônimo de "Estado democrático" aparece já no prefácio do Tratado Teológico-Político, em que afirma que teve a "sorte", ou melhor, a "rara felicidade de viver numa República, onde se concede a cada um inteira liberdade de pensar e de honrar a Deus como lhe aprouver e onde não há nada mais estimado nem mais agradável do que a liberdade", e enfatiza que essa liberdade não é apenas "compatível com a piedade e paz social" mas constitui sua condição necessária [...]. De fato, a liberdade que desfrutava na Holanda, no século XVII, era incomum na Europa daquele período, e isso teve um impacto significativo no seu pensamento político. Sua preferência fica evidente quando compara a "república livre" com a "monarquia" (HELANSKI; SILVA, 2014, p. 102).

\section{As mulheres na democracia espinosana}

Para finalizar, citamos os trechos especificados por Ellen Wood do Tratado Político na edição traduzida para a língua portuguesa que mostram as posições "machistas", "misóginas" e "sexistas" de Espinosa em relação às mulheres. Diante disso, é muito problemático que se recorra ao seu sistema de pensamento para fundamentar uma teoria democrática na atualidade (HELANSKI, 2017).

Pelo que se disse no artigo anterior, está claro que nós podemos conceber diversos gêneros de estado democrático. O meu desígnio não é tratar de cada um deles, mas só daquele onde têm o direito de voto e de aceder a cargos do estado absolutamente todos os que estão obrigados só às leis pátrias e que, além disso, estão sob jurisdição de si próprios e vivem honestamente. Digo expressamente os que estão obrigados só às leis pátrias, a fim de excluir os estrangeiros, que estão recenseados como sendo de outro estado. Acrescentei, além disso, que, à parte o estarem sujeitos às leis do estado, no resto estão sob jurisdição de si próprios, para excluir as mulheres 
e os servos, que estão sob o poder dos homens e dos senhores, assim como os filhos e os pupilos, porquanto estão sob o poder dos pais e dos tutores. Disse, enfim, e vivem honestamente, para excluir sobretudo os que, devido a crime ou a algum gênero torpe de vida, têm má fama (ESPINOSA, 2009, p. 138-139, grifo do autor).

O principal problema da teoria da democracia de Espinosa são essas exclusões que definem quem seriam os cidadãos em uma democracia. Quando Espinosa explica os motivos pelos quais exclui as mulheres do governo democrático, ele argumenta que as mulheres eram dependentes dos "homens" e que a sua presença na política poderia gerar discórdia e impedir que eles pensassem e agissem racionalmente (HELANSKI e SILVA, 2014, p. 107). O problema das mulheres participarem quando sob poder dos homens seria aumentar o poder de seus maridos ou pais e ainda representariam distrações (sendo responsáveis por erros de julgamento dos homens). Mas o mais grave é a forma como naturaliza as "diferenças" entre homens e mulheres, como podemos ver na citação seguinte: ${ }^{10}$

Talvez haja quem pergunte se é por natureza ou por instituição que as mulheres devem estar sob o poder dos homens. Com efeito, se for só por instituição que tal acontece, então nenhuma razão nos obriga a excluir as mulheres do governo. Porém, se consultarmos a própria experiència, veremos que isto deriva da sua fraqueza. Em parte nenhuma aconteceu, com efeito, os homens e as mulheres governarem juntos, mas em qualquer parte da terra onde se encontrem homens e mulheres vemos os homens reinarem e as mulheres serem governadas, vivendo assim ambos os sexos em concórdia. Pelo contrário, as amazonas, de quem se espalhou a fama de terem outrora reinado, não toleravam homens a morar no solo pátrio: amamentavam só as fêmeas e, se parissem machos, matavam-nos. [...] Se as mulheres fossem por natureza iguais aos homens e sobressaíssem igualmente pela fortaleza de ânimo e pelo engenho, que são aquilo em que acima de tudo consiste a potência humana e, por conseguinte, o direito, sem dúvida que, entre tantas e tão diversas nações, se encontrariam algumas onde os dois sexos governassem em paridade e outras onde os homens fossem governados pelas mulheres e educados de modo a terem, pelo engenho, menos poder. Como isto não aconteceu em parte nenhuma, é totalmente lícito afirmar que as mulheres, por natureza, não têm o mesmo direito que os homens e estão lhes necessariamente submetidas, de tal modo que não é possivel acontecer que ambos os sexos governem de igual modo e, muito menos, que os homens sejam governados pelas mulheres. Se, além disso, considerarmos os afetos humanos, ou seja, que os homens a maioria das vezes amam as mulheres só pelo afeto libidinoso e apreciam o seu engenho e a sua sabedoria só na medida em que elas sobressaem pela beleza, suportam com muita dificuldade que aquelas a quem amam se interessem de algum modo por outros, e coisas do mesmo gênero, facilmente veremos que não é possível, sem prejuízo grave da paz, homens e mulheres governarem de igual modo. Mas, sobre isto, já chega (ESPINOSA, TP-X, 2009, p. 139-140, grifos do autor).

\footnotetext{
${ }^{10}$ Alguns estudos têm abordado a questão das mulheres em Espinosa. Gullan-Whur (2002), por exemplo, diz que Espinosa nega os direitos políticos às mulheres comparando-as às crianças e aos "criados" - ambos sujeitos aos homens; que as mulheres são mentalmente inferiores aos homens; e, que as mulheres por sedu₹irem os homens tomam decisões políticas irracionais; essa exclusão "misógina" das mulheres da política era algo comum na época de Espinosa, entretanto, as Províncias Republicanas Unidas dos Países Baixos, acreditavam que se deveria "educar" as mulheres "inteligentes" e "excelentes estudantes". Um fato curioso é que Espinosa provavelmente conviveu com mulheres "eruditas", pois ele próprio disse que aprendeu latim e grego com uma menina holandesa de dez ou doze anos; assim, sua recusa em aceitar que as mulheres possam, intelectualmente, competir com os homens é, no mínimo, estranha. Não podemos deixar passar o argumento de Espinosa no Tratado Políticonem por "tolerância”, nem por "omissão", pois, depois de uma análise rigorosa das traduções de Espinosa, da sua metafísica e do seu tratado sobre a política, é possível concluir que "A recusa de Spinoza de garantir os direitos políticos das mulheres com base na sua fraqueza na habilidade intelectual e na sua danosa influência política é considerada ser uma das últimas coisas que ele escreveu antes da sua morte" e, continua, "eu acredito que Spinoza estava seduzido pela necessidade, em tempos de violenta revolta europeia, de mostrar a si mesmo um pragmatismo político proveitoso" (GULLAN-WHUR, 2002, p. 106-7). Gullan-Whur (2002) finaliza dizendo que "concluo que demonstrei definitivamente que o argumento da última página do Tratado Político é inconsistente com a doutrina geral da Ética e deve ser julgada como uma aberração filosófica embaraçosa e insignificante" (p. 107). Depois dessa reflexão gerada pelo contextualismo social podemos entender a defesa mais "filosófica" de Gullan-Whur e até mesmo a omissão de Antonio Negri e Marilena Chaú (sobre a misoginia de Espinosa), pois a visão de Espinosa sobre as mulheres estava condicionada pelo seu tempo, mas, seja por incongruências ou "aberração" filosóficas ou pelos limites históricos, ou mesmo por relevância de segunda ordem dentro do seu pensamento em geral, pensamos que os últimos parágrafos sobre as mulheres escritos por Espinosa antes de morrer invalida as interpretações emancipatórias e revolucionárias da sua teoria sobre a democracia - mas não invalida que Espinosa escreveu uma teoria sobre a democracia.
}

93 


\section{Considerações finais}

Embora seja importante considerar o pensamento de Espinosa como relevante para a Ciência Política - pois se adotássemos o critério da misoginia ou das afirmações machistas ou patriarcais para excluir os filósofos, não teríamos nenhum precursor, dado que Maquiavel, Hobbes, Locke e Rousseau também seriam excluídos - é importante não exagerar o caráter emancipador da teoria democrática de Bento Espinosa - como fizeram Marilena Chauí e Antonio Negri - sem levar em consideração os limites das reflexões do filósofo sobre a democracia.

Considerando que Espinosa tratou a República e a democracia como sinônimos, mais as regras de exclusão de democracia, mais o contexto social em que Espinosa viveu, a teoria sobre a democracia de Espinosa é ambígua e paradoxal, já que uma definição mais convencional das formas de governo diria que tal democracia parece ser uma aristocracia ou uma oligarquia, e que o que hoje chamam de democrático na sua teoria política não corresponde ao que ele escreveu e nem ao que ele viveu.

Assim, a leitura marxista da teoria política de Bento Espinosa feita a partir do contextualismo social mostra que a prática política que mais se aproximava do pensamento político de Espinosa era o governo republicano holandês das elites comerciais ricas. Essas reflexões analíticas sobre a interpretação marxista da teoria política de Espinosa feita por Ellen Meiksins Wood, juntamente às críticas que ela fez ao "marxismo espinosano", fornece novos modos de pensar os limites e as possibilidades do pensamento político do filósofo no contexto contemporâneo.

\section{Referências}

ESPINOSA, Bento. Tratado Político. São Paulo: Martins Fontes, 2009.

. Tratado Teológico-Político. São Paulo: Martins Fontes, 2004.

HARDT, Michael; NEGRI, Antonio. Multidão: guerra e democracia na era do Império. Rio de Janeiro: Record, 2005.

HELANSKI, Juliane. Contextualismo social na prática: a interpretação da teoria política de Bento Espinosa feita por Ellen Meiksins Wood. 161f. 2017. Dissertação (Mestrado em Ciências Sociais) Universidade Estadual do Oeste do Paraná, Toledo, 2017.

HELANSKI, Juliane; NERES, Geraldo Magela; SILVA, Vania Sandeleia Vaz da. Como estudar teoria política: textualismo, contextualismo linguístico e contextualismo social. In: DIAS, Andreia Vicente; BARBOSA, Paulo Henrique; SILVA, Vania Sandeleia Vaz (Orgs.). Conectando mundos, repensando relações. Porto Alegre: Evangraf, 2016.

HELANSKI, Juliane; SILVA, Vania Sandeleia Vaz. A inclusão dos pobres no sujeito político 'multidão': a carne monstruosa. In: $6^{\circ}$ Seminário nacional Estado e Políticas Sociais $2^{\circ}$ Seminário de Direitos Humanos. Toledo, 6., 2014. Anais... Toledo: Edunioeste, 2014.

NEGRI, Antonio. A Anomalia selvagem: poder e potência em Spinoza. Rio de Janeiro: Editora 34, 1981.

Spinoza subversivo. Madri: Akal, 2000.

GULLAN-WHUR, Margareth. Spinoza e a igualdade da mulher. Trad. Antonio Dilamar Araújo e Marsana Kessy. Theoria filosofoska institutionen, kungshuset lundagaird, v. 68, n. 2, p. 91-111, 2002.

SILVA, Vania Sandeleia Vaz. O contextualismo social de Neal Wood e Ellen Meiksins Wood: uma introdução. In: V Simpósio Paranaense de Ciências Sociais, 5., 2016. Anais... Toledo: Edunioeste, 2016. 
SILVA, Vania Sandeleia Vaz; HELANSKI, Juliane; Bento Espinosa (1632-1677) e a teoria das formas de governo. Tempo da Ciência, v. 21, n. 42, p. 95-108, 2014.

STRAUSS, Leo. Perseguição e a Arte de Escrever: e outros ensaios de filosofia política. São Paulo: É Realizações, 2015.

. Seminar on the Theological-Political Treatise. Chicago: University of Chicago, 1959.

WOOD, Ellen Meiksins. Citizens to Lords: a Social History of Western Political Thought from Antiquity to the Middle Ages. London: Verso, 2008.

2011a.

. Democracia contra capitalismo: a renovação do materialismo histórico. São Paulo: Boitempo,

Liberty and Property: a Social History of Western Political Thought from Renaissance to Enlightenment. London: Verso, 2011b.

2002.

. The Question of Market Dependence. Journal of Agrarian Change, v. 2, n. 1, p. 50-87, jan.

WOOD, Neal. Cicero's Social and Political Thought. California: University of California Press, 1991. John Locke and Agrarian Capitalism. California: University of California Press, 1984.

Reflections on Political Theory: a voice of reason from the past. New York: Palgrave, 2002.

1974.

. Socrates as Political Partisan. Canadian Journal of Political Science, v. 7, n. 1, p. 3-31, mar.

. The social history of political theory.n Political Theory, v. 6, n. 3, ago. 1978. 